\title{
Electrochemical Behavior of Selenium as Part of Composite Electrode in Sulfuric Acid Medium
}

Baeshov Abduali, Ivanov Nikolay, Myrzabekov Begzat*

D.V. Sokolsky Institute of Organic Catalysis \& Electrochemistry, Almaty,_Kunaev street-142, Republic of Kazakhstan.

${ }^{*}$ Correspondence to:

myrzabekbegzat@mail.ru

Master of Science

Department of electrochemical technology

"Institute of organic catalysis and electrochemistry named after

D.V.Sokolsky" JSC Almaty, _Kunaev street-142, Republic of

Kazakhstan

\section{ABSTRACT}

The method of productiion of the composite selenium-graphitic electrodes based on organic polymer binder was proposed. Electrochemical behavior of the elementary selenium as content of composite electrode in sulfuric acid medium was assessed. A formation of hydrogen selenide during the cathode polarization, and formation of selenite and selenate ions was shown. An influence of potential spread velocity, acid concentration, and temperature of electrolyte were evaluated. Effective activation power for cathode process was estimated using the temperature-cathodic method.

\section{Key words:}

Selenium; composite selenium-graphitic electrodes; cathode and anode polarization.

\section{Academic Discipline And Sub-Disciplines}

Electrochemical technology; electrochemical obtain product

\section{SUBJECT CLASSIFICATION}

Electrochemistry

\section{TYPE (METHOD/APPROACH)}

Original Articles

\section{Council for Innovative Research}

Peer Review Research Publishing System

Journal: Journal of Advances in Chemistry

Vol. 7, No. 3

editor@cirworld.com

www.cirjac.com, member.cirworld.com 


\section{INTRODUCTION}

Selenium and its compounding have been found widespread use in the industry and the medicine. For example, selenites and selenates are used as biological additives [1, 2], and various selenides - are typical semiconductors, of which photoelements are produced [3-5]. Elementary selenium during electrochemical treatment might be used for all oxidation degree selenium compoundings. Main product resulted from cathode polarization will be selenides, and from anode polarization - selenites and selenates. However, electrochemical behavior of the selenium is not completely evaluated.

\section{EXPERIMENTAL PART}

As elementary selenium possesses a high resistance, therefore in electrochemical practice for its characteristics and its compounding characteristics assessment the paste [6, 7], composite electrodes [8] and selenium in the form of light film are used [9]. In paste electrodes various organic substances are used as binders: olefins, Vaseline oil etc., they have viscous consistency, and surface-renewal is provided by cutting the top layer. These electrodes are easy to produce, however, their use is frequently limited by narrow temperature ranges. Composite electrodes are produced by curing or pressing of the graphitic powder and selenium and polymeric binder mixture. In this study one used the composite electrode where polymethylacrylate was served as binder. Figure 1 shows schematic view of the used electrode.

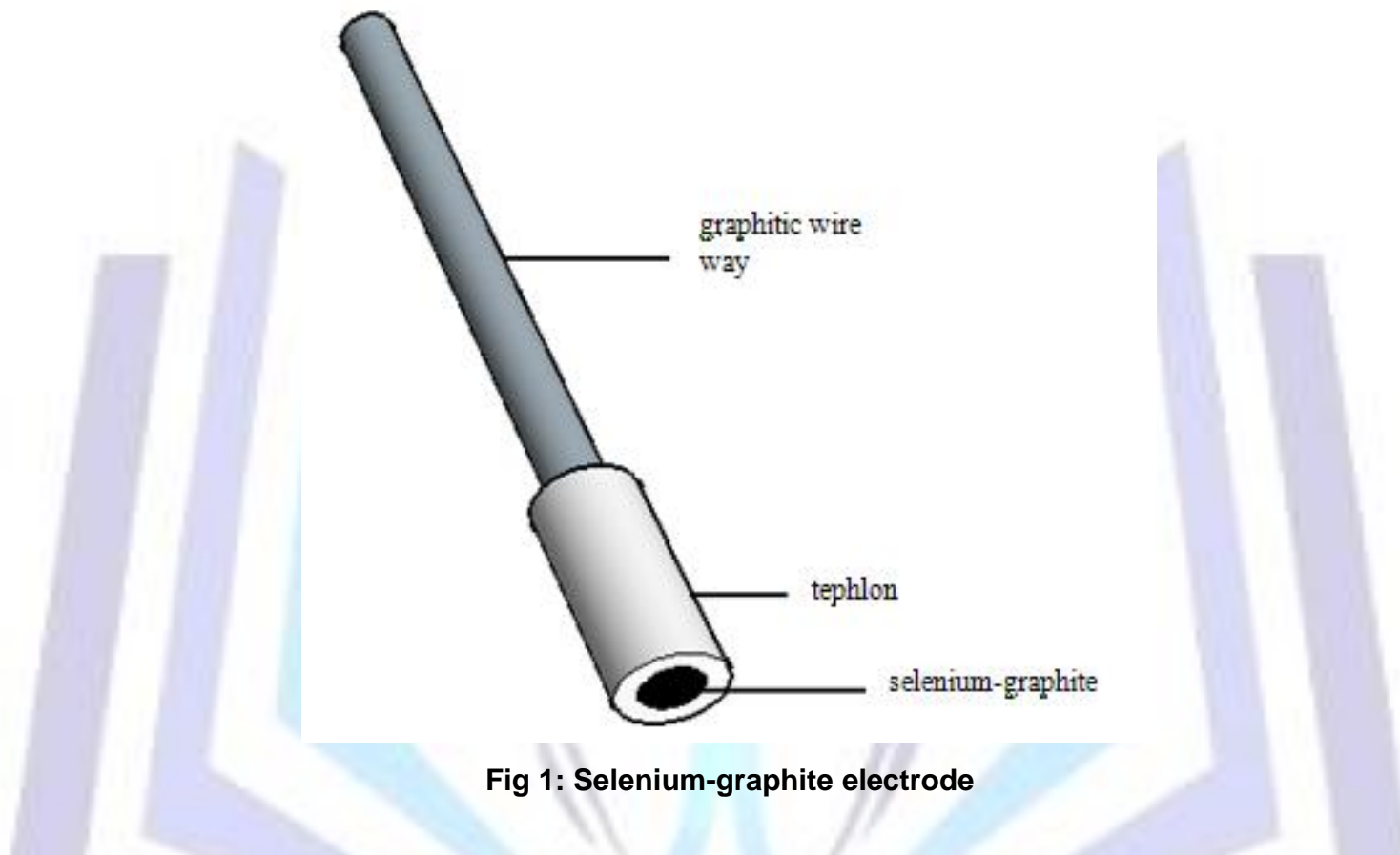

To produce an electrode a selenium-graphite mixture was used, with selenium - graphitis components proportion 2:1. Polymethacrylate was diluted in dichlorethane to obtain viscous mass, and then was mixed with selenium-graphite powder. Resulting paste was transferred into teflon cover, which contains as part a graphitic wire way from another side. After evaporation of the solvent and polishing, a hard selenium-graphite electrode with mirror surface and diameter $6 \mathrm{~mm}$ is obtained. This electrode possesses some benefits: is simple to produce, used binder is inert in strongly acidic and strongly alkaline electrolytes, temperature limit is up to $80^{\circ} \mathrm{C}$, and results are well reproducible.

Volt-amperometric measurements were conducted in thermostated triple electrode cell with divided anodic and cathodic spaces. Measurements were performed relatively to silver-chloride comparison electrode in concentrated $\mathrm{KCl}$ $(E=+203 \mathrm{mV})$. Wide surface platinum wire was used as counter-electrode.

\section{RESULTS AND DISCUSSIONS}

Figure 2 shows a cathodic-anodic potentiodynamic polarization curve of the selenium-graphite electrode in $1 \mathrm{M}$ sulfuric acid solution. Cathodic space of the potential area is characterized by 1 current wave in potential $-900 \mathrm{mV}$, which corresponds to double-electron selenium reduction with formation of hydrogen selenide according to reaction:

$$
\mathrm{Se}+2 \mathrm{H}^{+}+2 \mathrm{e}=\mathrm{H}_{2} \mathrm{Se}
$$




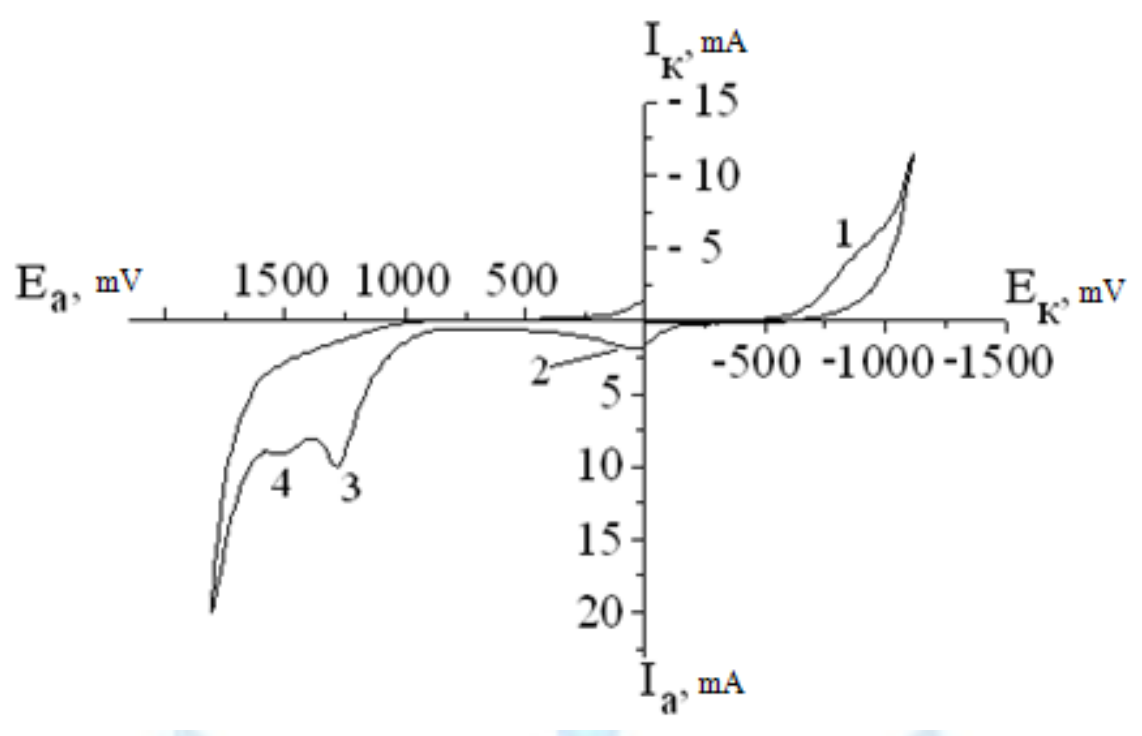

$1 \mathrm{M} \mathrm{H}_{2} \mathrm{SO}_{4}, \mathrm{t}=25^{\circ} \mathrm{C}, \mathrm{V}=100 \mathrm{mV} / \mathrm{sec}$

Fig 2: Cyclic potentiodynamic cathodic-anodic polarization curve

At further potential sweep in cathodic direction the process evolves with formation of polyselenides.

At potential sweep in anodic direction at potential $+50 \mathrm{mV}$ reverse hydrogen selenide oxidation is observed. Within the positive potential space there are 2 selenium oxidation maximum with formation of selenite- and selenate- ions according to reactions:

$$
\begin{aligned}
& \mathrm{Se}+3 \mathrm{H}_{2} \mathrm{O}-4 \mathrm{e}=\mathrm{SeO}_{3}{ }^{2-}+6 \mathrm{H}^{+} \\
& \mathrm{Se}+4 \mathrm{H}_{2} \mathrm{O}-6 \mathrm{e}=\mathrm{SeO}_{4}{ }^{2-}+8 \mathrm{H}^{+}
\end{aligned}
$$

It should be noted that formation of selenate ions is determined by direct selenium oxidation with release of six electrons, as selenite ion is not oxidated in the acid medium.

Figure 3 shows anodic-cathodic potentiometric polarization curve of selenium-graphite electrode in $1 \mathrm{M}$ sulfuric acid solution. At potential sweep in anode direction at potentials +1230 and $+1490 \mathrm{mV}$ reactions 2 and 3 take place. At potential sweep in cathodic direction a first current maximum is observed at potential $-350 \mathrm{mV}$, and corresponds to reduction reaction of the quadrivalent selenium, formed in anodic cycle:

$$
\mathrm{SeO}_{3}{ }^{2-}+6 \mathrm{H}^{+}+4 \mathrm{e}=\mathrm{Se}+3 \mathrm{H}_{2} \mathrm{O}
$$
reaction 1.

Cathodic current maximum at potential $-600 \mathrm{mV}$ corresponds to reduction of as-deposited selenium according to 


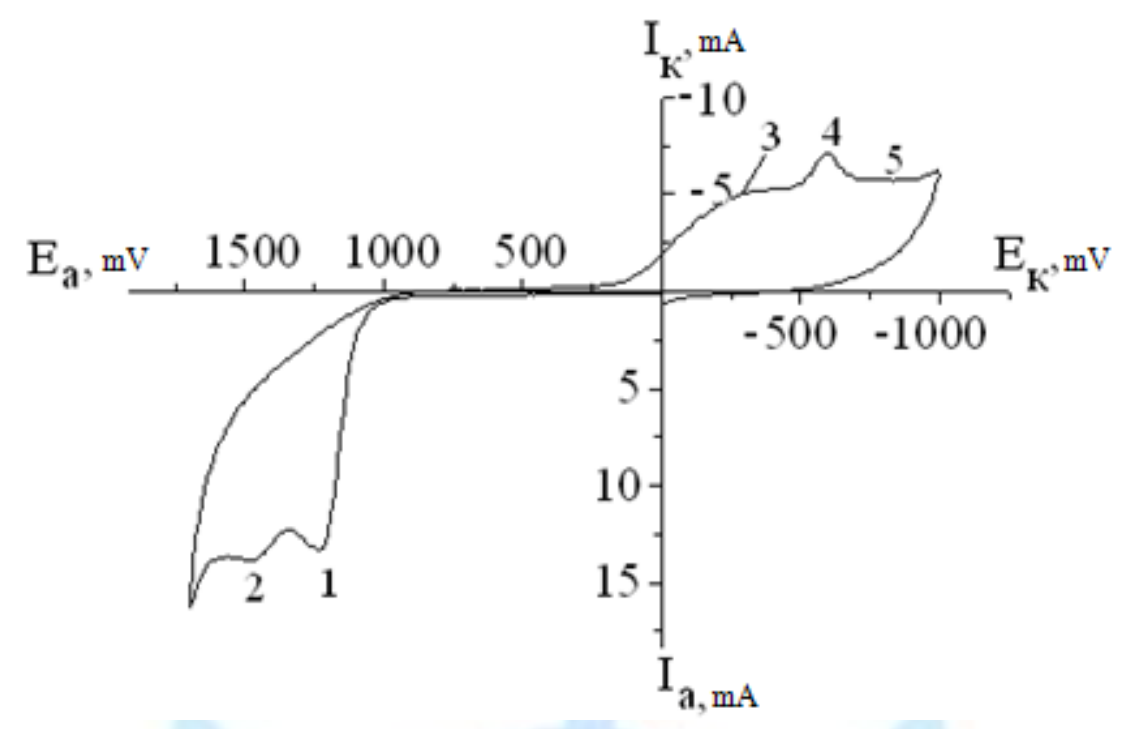

$1 \mathrm{M} \mathrm{H}_{2} \mathrm{SO}_{4}, \mathrm{t}=25^{\circ} \mathrm{C}, \mathrm{V}=100 \mathrm{mV} / \mathrm{sec}$

Fig 3: Cyclic potentiodynamic anodic-cathodic polarization curve

Figure 4 shows cathodic curves of the elementary selenium reduction at various potential sweep velocities. In accordance to Figure 4 cathodic maximum measurement is increased, provided that $E_{p}$ displaces from lgV to the negative side.

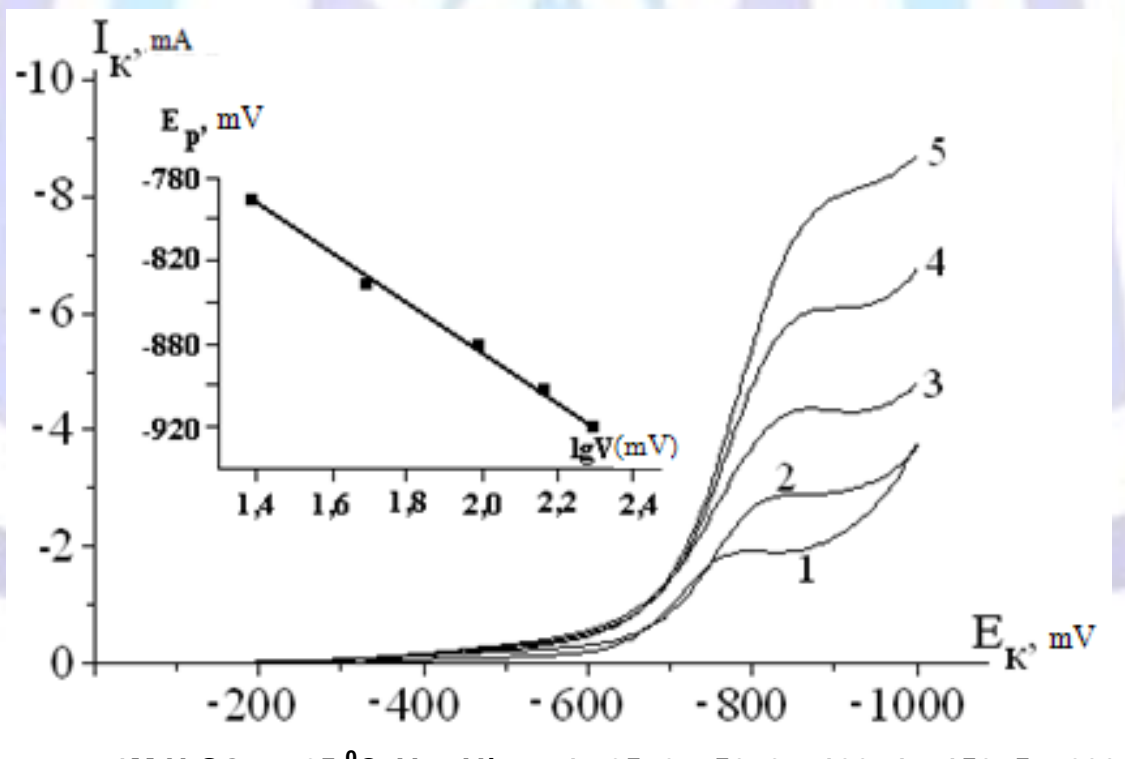

$1 \mathrm{M} \mathrm{H}_{2} \mathrm{SO}_{4}, \mathrm{t}=25{ }^{0} \mathrm{C}, \mathrm{V}, \mathrm{mV} / \mathrm{sec}: 1-25 ; 2-50 ; 3-100 ; 4-150 ; 5-200$;

Fig 4: Cathodic potentiodynamic polarization curves at various potential sweep velocity

$\lg \mathrm{l}_{\mathrm{p}} / \mathrm{lgV}$ dependency analysis has shown that angular coefficient for peak was 0,7 , such overestimated measurement might be induced by surface development due to electric dissolution of the elementary selenium.

An influence of the sulfuric acid concentration on the electric reduction process of the elementary selenium was evaluated. As seen from Figure 5, there is no hydrogen selenide formation wave; however, there is no hydrogen release, as well. In that case, selenium moves into solution in form of polyselenides. At sulfuric acid concentration $0,16 \mathrm{M}$ a hydrogen selenide formation cathodic wave is clearly seen, and stops to rise after sulfuric acid concentration reaches 0,25 M. 


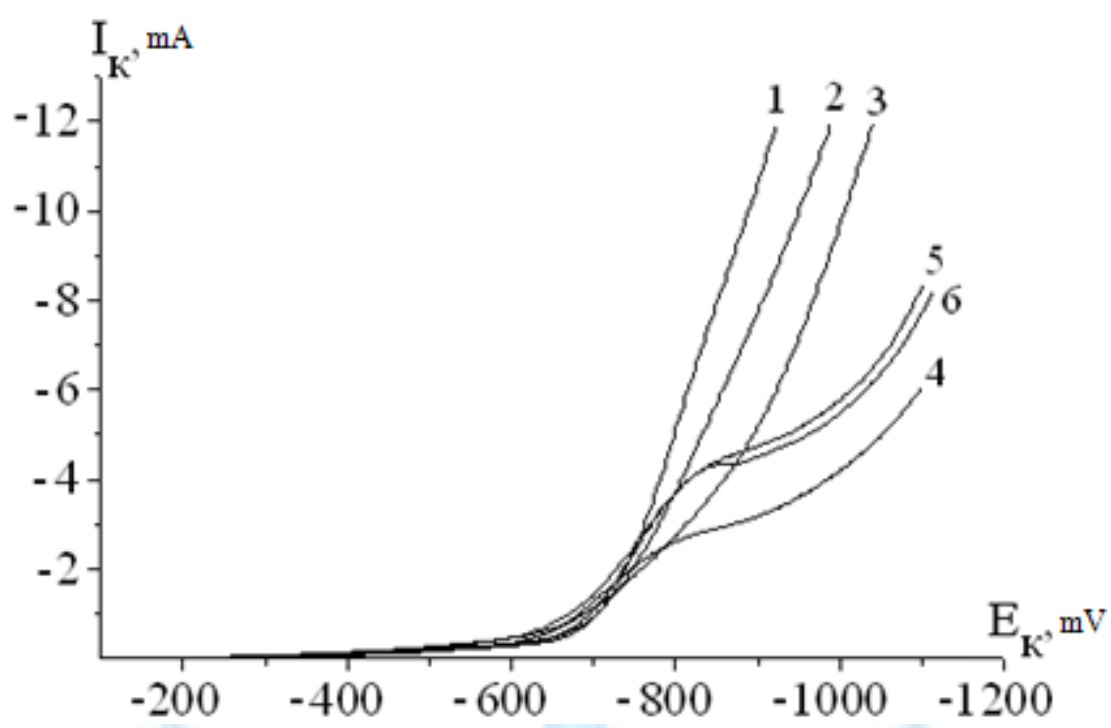

$\mathrm{t}=25^{\circ} \mathrm{C}, \mathrm{V}=100 \mathrm{mV} / \mathrm{sec}, \mathrm{C}, \mathrm{M}: 1-1 \mathrm{M} \mathrm{Na}_{2} \mathrm{SO}_{4} ; 2-4^{\star} 10^{-6} ; 3-4^{\star} 10^{-2} ; 4-16^{\star} 10^{-2} ; 5-25^{\star} 10^{-2} ; 6-50^{\star} 10^{-2}$;

Fig 5: Cathodic polarization curves of the selenium-graphite electrode at various sulfuric acid concentrations

An influence of the temperature on cathodic curve slope was evaluated. As seen from the Figure $6 \mathrm{a}$, the higher the temperature, the more significant increase of the current maximum with simultaneous potential sweep in cathodic direction, which indicates facilitation of cathodic processes. In accordance to Figure $6 \mathrm{~b}$, an effective activation energy in overload within first peak area was estimated using temperature-kinetic method, and was 15,5, 15,3, and 14,5 kJ/mol respectively, which indicates diffusion process control.
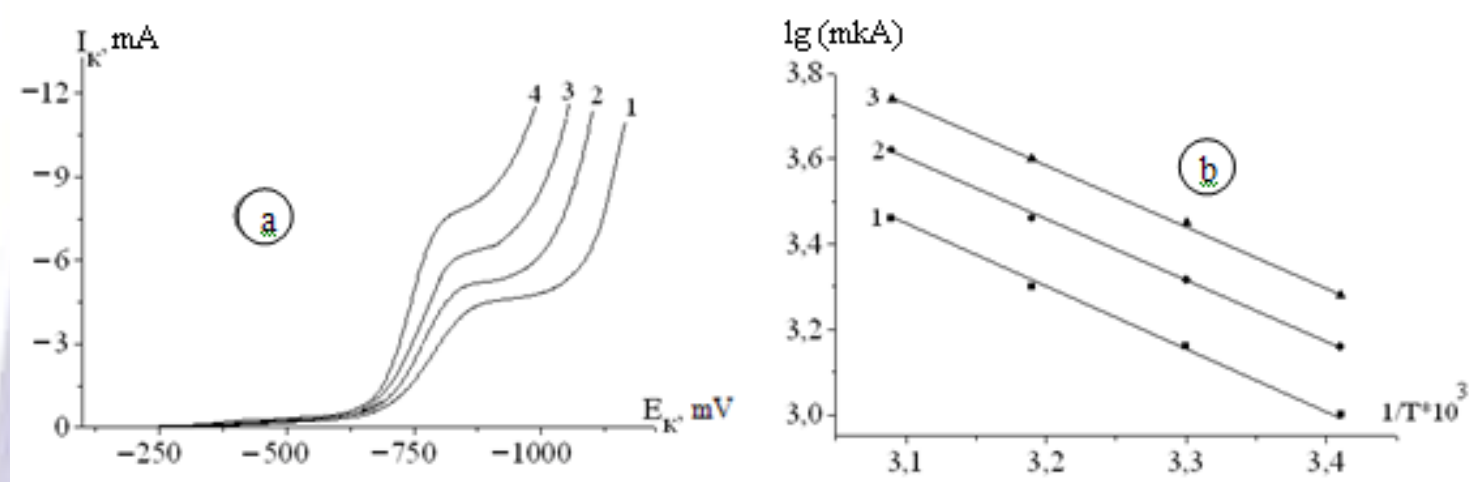

$1 \mathrm{M} \mathrm{H}_{2} \mathrm{SO}_{4}, \mathrm{~V}=100 \mathrm{mV} / \mathrm{sec}, \mathrm{t},{ }^{0} \mathrm{C}: 1$ - 20; 2 - 30; 3-40; 4 - 50;

a - cathodic potentiodynamic polarization curves at the various temperatures of the electrolyte;

b - dependency of Igl from the temperature at the various overload, $\Delta \mathrm{E}, \mathrm{mV}: 1$ - 710; 2 - 730; 3 - 750;

Fig 6: Influence of the temperature on the electroreduction process - Se (IV) to $\mathrm{Se}^{0}$

Selenium-graphite electrode behavior in sulfuric acid solutions was investigated further.

Figure 7 shows anodic curves of the elementary selenium oxidation at the various sweep velocity. In accordance to Figure 7 , the first anodic maximum measurement is increased, and the second - doesn't change, provided that $E_{p}$ is displaced from lgV to positive side. 


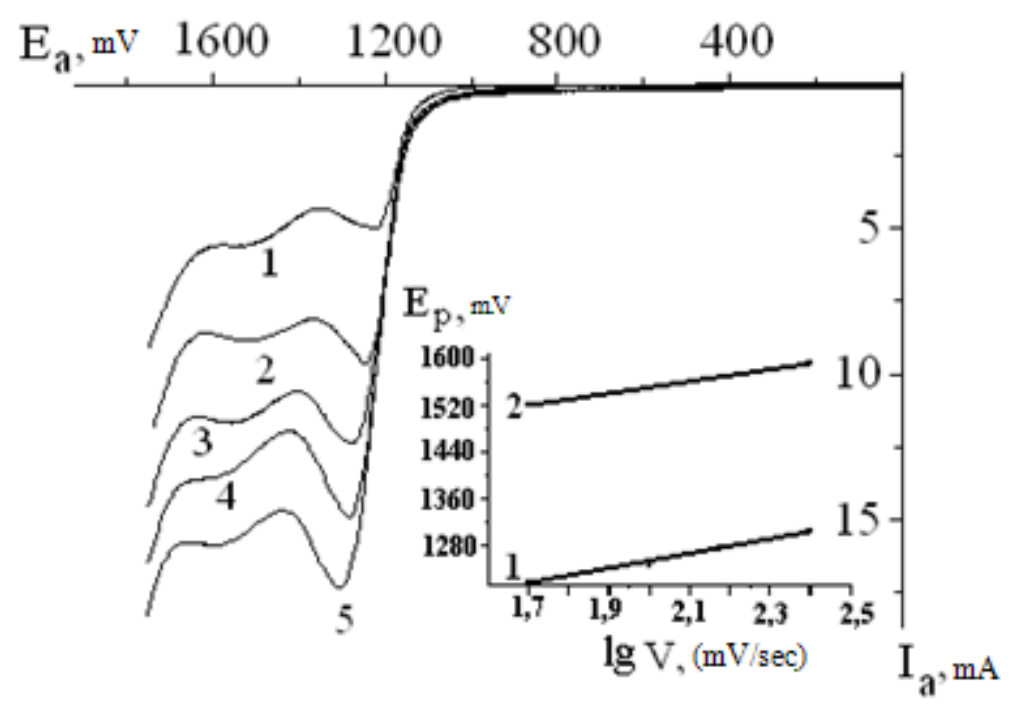

$0,5 \mathrm{M} \mathrm{H}_{2} \mathrm{SO}_{4}, \mathrm{t}=25{ }^{\circ} \mathrm{C}, \mathrm{V}, \mathrm{mV} / \mathrm{c}: 1-50 ; 2-100 ; 3-150 ; 4-200 ; 5-250$;

Fig 7: Anodic potentiodynamic polarization curves of the selenium-graphite electrode at various potential sweep velocity

$\lg \mathrm{l}_{\mathrm{p}} / \mathrm{lg} \mathrm{V}$ dependency analysis has shown that angular coefficient for the first peak was 0,75 , such overestimated measurement might be induced by surface development due to electric dissolution of the elementary selenium. Angular coefficient for the second peak was 0 . This deceleration of the anodic reaction might be related to free electron depletion from the selenium surface layer.

An influence of the sulfuric acid concentration on the electric reduction process of the elementary selenium was evaluated. As seen from Figure 8, the higher the sulfuric acid concentration, the higher the anodic maximum increase with simultaneous peak potential displacement in cathodic direction, which indicates facilitation of the anodic process.

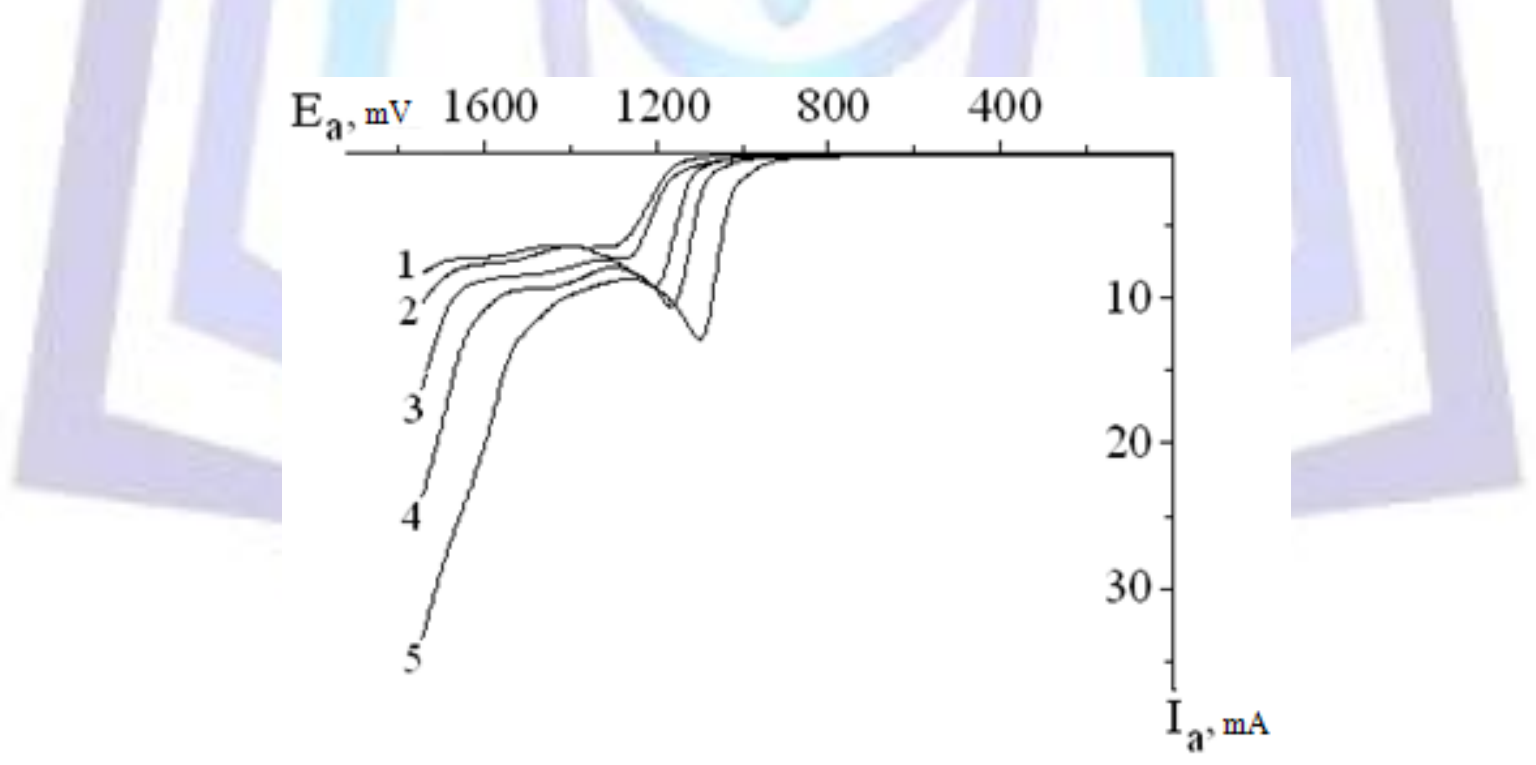

C, M: $1-0,1 \mathrm{M} ; 2-0,5 ; 3-1,0 ; 4-2,0 ; 5-4,0$;

Fig 8: Anodic polarization curves of the selenium-graphite electrode at various sulfuric acid concentrations

An influence of the temperature on cathodic curve slope was evaluated. As seen from the Figure 9a, the higher the temperature, there is not only the more significant an increase of the anodic maximum, but the first peak is degenerated. However, in accordance to Figure 9b, curve 5 cycling shows that at potential sweep in cathodic direction selenistic acid reduction is observed, and, therefore, although first peak degeneration, the process described by reaction 2 elapses.

\section{CONCLUSIONS}


Materials presented show that under cathodic selenium polarization in sulfuric acid medium a hydrogen selenide is formed, which might serve as precursor component for metal selenides synthesis. Under anodic polarization both $\mathrm{Se}(\mathrm{IV})$, and Se (VI) are formed. It was shown that these processes are substantially influenced by sulfuric acid concentration and electrolyte temperature.

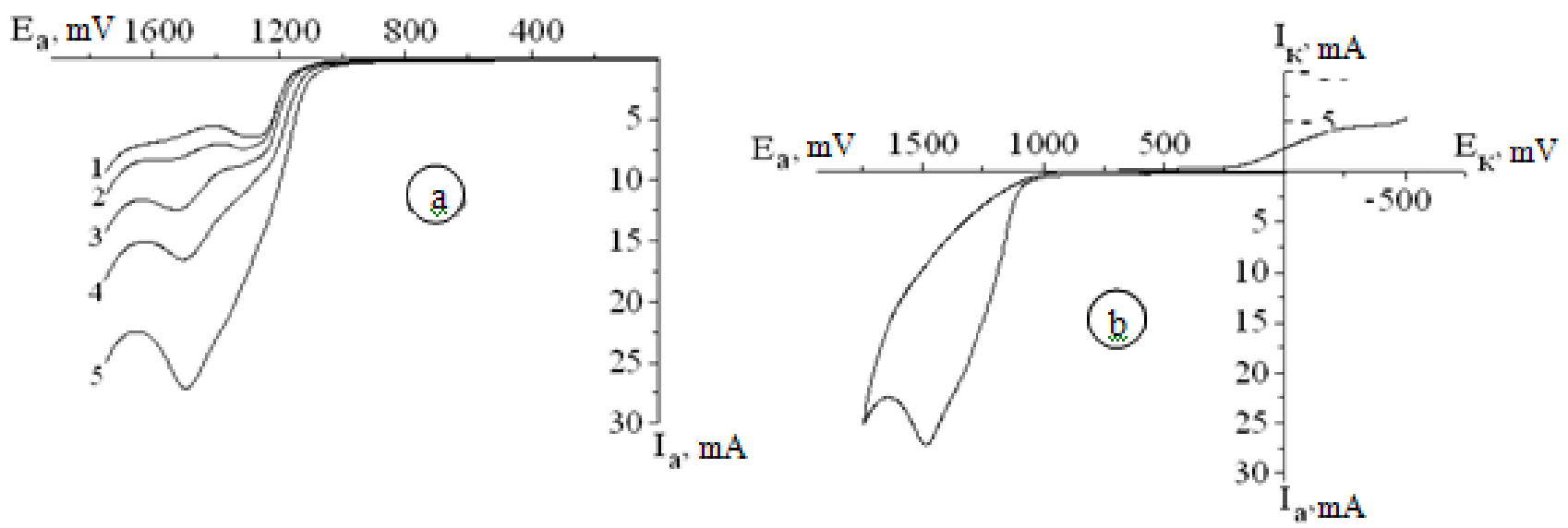

$0,5 \mathrm{M} \mathrm{H}_{2} \mathrm{SO}_{4}, \mathrm{~V}=100 \mathrm{mV} / \mathrm{c}, \mathrm{t},{ }^{0} \mathrm{C}: 1-20 ; 2-30 ; 3-40 ; 4-50 ; 5-60$

Fig 9: Anodic potentiodynamic polarization curves at the various electrolyte temperatures

\section{References}

1. Thressa C Stadtman. Biological functions of selenium. Trends in biochemical sciences 1980; 5(8): $203-206$.

2. Baraboi V.A, Shestakova E.N. Selenium: The biological role and antioxidant activity. Ukr Biokhim Zh. 2004; 76(1): 2332.

3. Gurinovich L.I, Artemyev M.V, Stupak A.P, Prislopskii S.Ya, Gaponenko S.V. Photoinduced processes in nanocrystals of cadmium selenide in an external electric field. Journal of Applied Spectroscopy 2012; 78(6): 893-900.

4. Dergacheva M.B, Urazov K.A, Pen'kova N.V. Electrodeposition of CulnSe2 films onto a molybdenum electrode. Russian Journal of Applied Chemistry 2010; 83(4): 601-605.

5. Belykh A.V, Kaputkina S.Yu, Mikhailov M.D, Tverjanovich A.S. Photoinduced changes of the rate of dissolution of bilayer films of chalcogenide glasses. Glass Physics and Chemistry 2012; 38(2): 185-189.

6. Carbonnelle P, Lamberts L. Electrochemical study of the copper-selenium system using carbon paste electrode. Electrochimica Acta 1992; 37(8): 1321-1325.

7. Gobert E, Vittori O. Electrochemical study of PbSe using the carbon pasteelectrode technique. Electrochimica Acta 1988; 33(2): 245-250.

8. US Patent No. US 2428055. Composite selenium electrode. Von HA, Schulman JH; Published on 30.9.1947.

9. Nagaosa Y, Zong P, Kamio A. Selenium-coated carbon electrode for anodic stripping voltammetric determination of copper (II). Microchimica Acta 2009; 167(3-4): 241-246. 